\title{
The Preparation of Ag Nanoparticles/Graphene Nanocomposites with Polydopamine as Coupling Agent for Enhanced Detection of $\mathrm{H}_{2} \mathrm{O}_{2}$
}

\author{
Zhi-Min Ma, Bing-Tao Wang, Ke-Ying Cui, Ye Wan, Su-Juan Li ${ }^{*}$ \\ Henan Province Key Laboratory of New Optoelectronic Functional Materials, College of Chemistry \\ and Chemical Engineering, Anyang Normal University, Anyang, 455000, Henan, China \\ "E-mail: lemontree88@163.com
}

doi: $10.20964 / 2019.07 .30$

Received: 1 March 2019 / Accepted: 22 April 2019 / Published: 10 June 2019

In this paper, a new Ag nanoparticles (AgNPs)/graphene nanocomposites with polydopamine (PDA) as coupling agent was electrochemically synthesized and has been used as electrode modifications for the electrochemical detection of $\mathrm{H}_{2} \mathrm{O}_{2}$. The structural characterizations clearly showed that small sized and highly dispersed AgNPs were electrodeposited on reduced graphene oxide (RGO) with the help of PDA agent. The obtained AgNPs/PDA/RGO nanocomposites exhibited higher electrocatalytic activities toward reduction of $\mathrm{H}_{2} \mathrm{O}_{2}$ compared with the AgNPs/RGO composites without involvement of PDA. The AgNPs/PDA/RGO nanocomposites presented excellent electrochemical sensing performance for detection of $\mathrm{H}_{2} \mathrm{O}_{2}$ with wide linear concentration range, high detection sensitivity, good selectivity and excellent reprodutibility and stability. The successful application of AgNPs/PDA/RGO nanocomposites in human serum samples for the detection of $\mathrm{H}_{2} \mathrm{O}_{2}$ was also demonstrated.

Keywords: Silver nanoparticles; Graphene; Hydrogen peroxide; Polydopamine; Electrochemical sensor

\section{FULL TEXT}

(C) 2019 The Authors. Published by ESG (www.electrochemsci.org). This article is an open access article distributed under the terms and conditions of the Creative Commons Attribution license (http://creativecommons.org/licenses/by/4.0/). 